Weapons in space

\section{Soviet alarm about star wars}

\section{Washington}

SOVIET alarm about the US strategic defence initiative (SDI), or "Star Wars", is the apparent explanation for an unusual document on directed energy weapons now being made widely available through Soviet sources. The document* is credited to the Committee of Soviet Scientists for Peace against the Nuclear Threat and is available in a good English translation. After a sombre review of the potential of a variety of directed energy weapons, the report concludes that the deployment of space-based anti-missile systems would increase the incentive for pre-emptive first strikes and worsen the danger of wrong decisions in a political crisis. It would also, according to the report, stimulate the proliferation of alternative delivery systems such as cruise missiles, which may be less vulnerable to space-based attack.

The two coordinators of the report are Academician R.Z. Sagdeyev, director of the Institute of Space Research, and Dr A.A. Kokoshin, deputy director of the Institute of USA and Canada Studies, both at the USSR Academy of Sciences. A dozen or so "experts" are also credited; some are better known, however, for their political than for their scientific achievements. Copyright is claimed by the Institute of Space Research.

The report concludes that the hydrogen fluoride (HF) chemical laser has the greatest potential for use against ballistic missiles in the next few years. Referring to scientific reports in the open literature, it concludes that a basic space-based antimissile system (SBAM) with 5-MW lasers

-A Space-based Anti-missile System with Directed Energy Weapons: Strategic, Legal and Political Implications. using 4-metre focusing mirrors is within present technological capability and could be deployed within 8 to 10 years. Freeelectron and excimer lasers are not yet sufficiently developed but might be useful by the year 2000 , if powered by space-based nuclear reactors. The nuclear-pumped $\mathrm{X}$-ray laser, however, is thought to have little potential; calculations suggest it might be able to focus sufficient power to destroy a missile at about $3 \mathrm{~km}$ - "not much above the effective range of the nuclear explosion itself"'. The aiming system for such a device would have to be tested in space in defiance of the existing anti-ballistic missile treaty.

Charged particle beams are quickly dismissed because they are bent by the Earth's magnetic field; of more use might be a beam of neutral hydrogen atoms produced by charge-exchange from an accelerated beam of $\mathrm{H}^{-}$ions. But the energy of ions required, around $1 \mathrm{GeV}$, would need accelerators several hundred metres long. Although the pointing accuracy required for a directed energy weapon has already been demonstrated in non-military applications, the need for high speed -0.1 seconds on each missile would be an entirely new technical challenge.

Despite the feasibility of deploying HF lasers within 10 years, the report's discussion of the logistics of an anti-missile system suggests that the technology for anything approaching complete effectiveness is still many years away. A system with 18 stations in polar orbit using 5-MW lasers, needing 126 shuttle missions for deployment, would be able to hit only 15 missiles in 100 seconds. The more powerful

\title{
Status of peace document in doubt
}

THE document issued by the Committee of Soviet Scientists for Peace against the Nuclear Threat, although ostensibly a spontaneous initiative, clearly has high official approval. The official Tass and Novosti news agencies have given it wide publicity, and Academician R.Z. Sagdeyev and Dr A.A. Kokoshin are both highly placed in the Soviet hierarchy. Kokoshin was at the centre of a diplomatic row last year when the Canadian government refused him an entry visa to attend a scientific conference. The technical detail in the report is, moreover, of a kind that would normally have been classified as militarily sensitive in the Soviet Union. Although ostensibly only an analysis of options open to the United States, the document draws on data that must have been accumulated by the Soviet military.

During the past eighteen months, the Soviet Union has produced a number of special interest "initiatives" in the defence of peace, among which the scientists' and physicians' committees are the most significant. How far such appeals are orchestrated is a delicate question.

What is clear, however, is that even when a Soviet scientist wishes to speak out against nuclear weapons, he cannot with impunity attack his own country's policy.

Last week, Academician Vitalii Goldanskii published an article supporting what he called the "noteworthy initiative" of the US Nobel laureate Glenn Seaborg, who has advocated the signing of a complete nuclear test-ban to commemorate the 40th anniversary of Hiroshima and Nagasaki. Goldanskii found it necessary, however, to begin by asserting that "it is the United States that is above all to blame" for the lack of a comprehensive test-ban treaty, and to condemn Washington's claims that "it is impossible to ensure effective control" over such a treaty.
800 -tonne lasers that would increase this figure to 1,000 missiles are beyond present technology, according to the report. Particle accelerators, which would weigh more than 1,000 tonnes, appear to be even farther away. The cost of a feasible though far from perfect system employing 800 -tonne lasers is put at up to $\$ 2$ million million, in agreement with US estimates.

The report lists a number of countermeasures that might increase the cost beyond this: they include ablative coatings on missiles, false missiles, obstacle clouds placed in the orbit of an anti-missile station; space mines kept in orbit close to the station; "sprint" missiles that travel through the atmosphere at up to $5 \mathrm{~km}$ per second; and ground-based lasers, which do not suffer from the same size and weight restrictions. The vulnerability of antimissile systems is said to add to their destabilizing effect, and the development of countermeasures is (obscurely) said to increase likely civilian casualties in the event of a nuclear exchange.

As if all this were not enough, the report ends with a tug at the reader's social conscience: the funds used to develop an anti-missile system could be better used for "peaceful purposes" to benefit mankind. And - scientists please note - further development of anti-missile technology would make scientific collaboration in space impossible.

Nature's copy of the report was obtained from the Soviet Embassy in Washington.

Tim Beardsley

\section{Pharmaceuticals \\ New institute}

\section{Washington}

FIDIA SpA, the Italian pharmaceuticals company, has announced its intention to provide $\$ 62$ million over 20 years to establish a new neurosciences institute at Georgetown University in Washington DC. The agreement is one of the largest ever corporate/university research ventures. The institute would be staffed by Georgetown University faculty and would house fundamental research in neuroanatomy and physiology as well as neuropharmacology.

Fidia says it already devotes 20 per cent of its income to neuroscience research in Italy, and that the new institute would gain it a foothold in US science and provide academic exchanges with Fidia researchers. A spokesman stressed that there would be no restrictions on the free and timely publication of research results from the new institute, which is to be called the Fidia Georgetown Institute for the Neurosciences. There are plans for 25,000 square feet of laboratory space.

The post of director of the institute has been offered to Dr Erminio Costa, now at Saint Elizabeth's Hospital, also in Washington DC. 